Article

\title{
The Potential of Juniperus thurifera to Sequester Carbon in Semi-Arid Forest Soil in Spain
}

\author{
Elena Charro *, Amelia Moyano and Raquel Cabezón
}

Area de Didáctica de las Ciencias Experimentales, Universidad de Valladolid, Valladolid 47011, Spain; gardini@dce.uva.es (A.M.); gardini@pvs.uva.es (R.C.)

* Correspondence: echarro@dce.uva.es; Tel.: +34-983-423-466

Received: 20 July 2017; Accepted: 2 September 2017; Published: 6 September 2017

\begin{abstract}
The main purpose of this work is to show the influence of vegetation in the storage and stabilisation of organic carbon in semi-arid Juniperus thurifera (J. thurifera) forest soil in central Spain. The variability of the organic matter storage with factors such as sex, trunk diameter and the protection of the canopy of the tree has been analysed. The distribution of the soil organic carbon (SOC) into different fractions has also been determined, in order to estimate the stability of the organic matter. The results show that the SOC concentration has no dependence on the sex of the tree, but it increases with the diameter of the trunk and under the protection of the tree canopy. This study found that the organic matter of the J. thurifera forest soil has a high proportion of recalcitrant organic fraction, humin, which suggests that, given its organic matter stability, J. thurifera forest soils could be a real carbon sink. Consequently, the conservation of this type of old forest ecosystem is important for promoting carbon sequestration.
\end{abstract}

Keywords: Juniperus thurifera; forest soils; organic carbon stability; humus fractions

\section{Introduction}

Climate change is one of today's most important global environmental issues, which directly affects all natural ecosystems and socio-economic systems [1]. One of the main strategies to mitigate climate change is based on the soil functioning as a carbon (C) sink [2]. Consequently, the number of studies on soil organic carbon (SOC) changes in different ecosystems is increasing [3-7].

Nowadays, forests are covering about $30 \%$ of the terrestrial landscape in the world [8], and they are the main pool for terrestrial $C$ stock, where the main $C$ storage occurs in the forest biomass and soils [9]. In the forest ecosystem, $C$ storage occurs in the tree aerial biomass-stems, branches and foliage-ground vegetation [10], tree-root biomass, forest floor, and soil [11]. In the forest ecosystem, the soil C stock is important given that it is in dynamic equilibrium with the vegetation [12]. Furthermore, in terrestrial environments, soil organic matter (SOM) is the largest organic $\mathrm{C}$ pool; the quantity and quality of organic $C$ in soils can be affected by vegetation through influencing the inputs and outputs of SOM [13]. Through differences in litter quality, plant species have an influence on the storage and dynamics of $C$ in soils, as reported in several previous studies [14].

Thus, forest management is accepted as a tool for removing atmospheric $\mathrm{CO}_{2}$ [15]. For this reason, some authors [16] have studied whether unmanaged forests have higher contributions to climate change mitigation than managed forests because of their potential of $C$ sequestration in living biomass and soil, which is the role of the old-growth forests as global C sinks as pointed out by some studies [17]. Some publications also show how the management of the forest soils for agricultural purposes changes the soil $\mathrm{C}$ equilibrium [18]. Thus, given that changes in land use and fire events cause the loss of $C$, which is emitted to the atmosphere [19], it is important to know the $C$ stock in different pools and if this $C$ is allocated into labile or stable soil $C$ components. 
The storage of $\mathrm{C}$ in soils is mainly in the form of SOM [20], for which humic substances comprise a major proportion [21]. Furthermore, given the different chemical properties of humic substances, several studies have focused on developing processes for the separation of their fractions [22]. On the basis of the different solubility of acids in the components of the organic matter, labile and recalcitrant pools, which have different turnover times, can be separated [23]. Humic substances have a high C content and long turnover times; that is, a long time is needed to form them. These substances can be fulvic acid, humic acid, and humin. Fulvic acids are the most abundant humic substances in the soils, given their solubility [24], and this property is important in order to know more about their environmental behaviour [25]. Humin represents the most recalcitrant fraction of organic matter.

For this reason, estimating, quantitatively, the influence of tree species on C stored in forest soils is one of the issues that is receiving a significant amount of attention, but how to optimise $\mathrm{C}$ sequestration and how vegetation affects the stability of SOC are less understood. However, recently, some investigations have been conducted in order to analyse the influence of tree species on the vertical distribution of the labile and recalcitrant C [13]; some of these studies were conducted on Mediterranean forests [26] and in semi-arid environments [27].

In order to mitigate global warming, $\mathrm{C}$ sequestration has been promoted by implementing effective measures for the conservation of old forest ecosystems and new plantations [28]. A particular case is for arid and semi-arid ecosystems, for which the impacts of climate and atmospheric $\mathrm{CO}_{2}$ changes are still unclear [29]. For these reasons, thurifera forests, which are usually old and semi-arid ecosystems, can play an important role in C sequestration. J. thurifera, a tree of the Cupressaceae family, is found mainly in Morocco, Algeria, Spain, and certain regions of France and Italy. The forests of these trees are important from different points of view: ecological, socioeconomic, floristic, and cultural perspectives [30]. Given this interest, several studies have been published on this millenarium tree [31-36], the most recent works by García-Morote et al. [37] and Lahouel et al. [38]. However, semi-arid Mediterranean soils are still not studied enough, in particular, Juniperus woodlands [37].

In this work, the influence of $J$. thurifera on the storage and stabilisation of organic $\mathrm{C}$ in soil was analysed. For this purpose, the variability of the organic $C$ concentration in soil samples was studied considering the effect of several factors, such as the sex of the tree, the diameter of the tree trunk, and the canopy effect. For the analysis of the stability of the organic matter, the distribution of the recalcitrant organic matter fractions in the soil profile was obtained. Finally, a better quantitative and qualitative knowledge of the SOC in a thuriferous juniper semi-arid forest has been obtained, which should be useful for evaluating the role of this forest soil in $C$ sequestration.

\section{Materials and Methods}

\subsection{Site Description}

The study area, the "Enebral forest" (Figure 1), is located at Sierra de Cabrejas in Soria Province (central Spain), and is predominantly covered by J. thurifera, partially mixed with Juniperus communis L., Quercus ilex subsp. ballota (Desf). Samp., pines (Pinus sylvestris L. and Pinus pinaster Aiton), and with scarce vegetation of Lavandula latifolia, Medicus, and Thymus zygis L. The main characteristics of the study site are shown in Table 1. The site has a continental climate, with dry summers (June to September) and cold winters. The soils of this forest have been classified as Lithic Eutrudepts and Lithic Xerorthents according to the United States Department of Agriculture (USDA) [39] classification. The forest has a density of 209 trees/ha, and the average distance between trees is $12 \mathrm{~m}$. A forest inventory was performed in circular plots of $5000 \mathrm{~m}^{2}$, for which all trees with a diameter at breast height $(\mathrm{DBH})$ of greater than $7 \mathrm{~cm}$ were counted. 


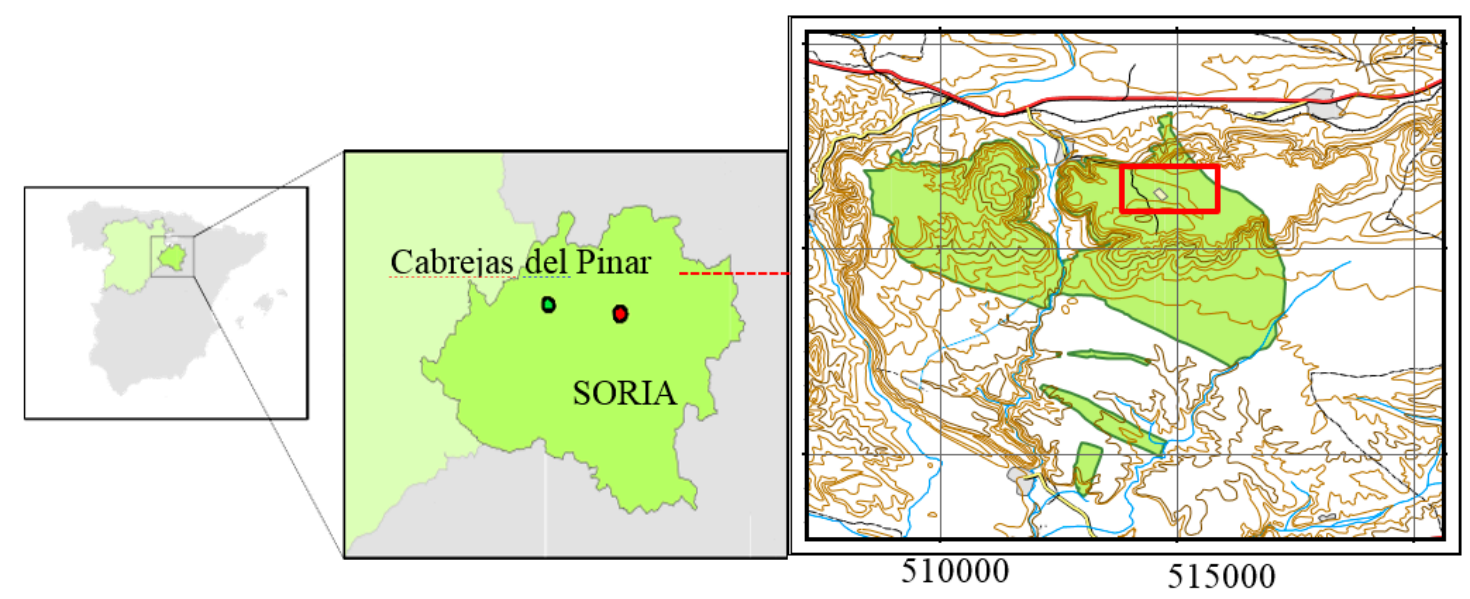

Figure 1. Maps for locating the area under study, the "Enebral forest" (red square).

Table 1. General characteristics of the site under study.

\begin{tabular}{cc}
\hline Location of Sierra de Cabrejas & Cabrejas del Pinar (Soria, Spain) \\
\hline Altitude (m.a.s.l.) & 1258 \\
Slope (\%) & 5 \\
Geological substrate & Upper Cretaceous (calice) \\
Soil type & 209 \\
Stand density (Trees/ha) & Lithic Eutrudepts and Lithic Xerorthents \\
Vegetation type (principal) & Juniperus thurifera L. \\
Rainfall (mm/year) & 996 \\
Average annual mean temperature $\left({ }^{\circ} \mathrm{C}\right)$ & -3.2 \\
Average winter temperature $\left({ }^{\circ} \mathrm{C}\right)$ & 18.3 \\
Average summer temperature $\left({ }^{\circ} \mathrm{C}\right)$ &
\end{tabular}

m.a.s.l., Meters above sea level.

\subsection{Soil Sampling}

In order to take soil samples, a total number of 40 trees were selected according to their sex and their trunk diameter. According to the diameter $(d)$ of the trunk, four groups of trees were taken into account, described as (A) trees with trunk diameters of between 7 and $10 \mathrm{~cm}$, (B) trees with trunk diameters of between 10 and $20 \mathrm{~cm},(C)$ trees with trunk diameters of between 20 and $30 \mathrm{~cm}$, and (D) trees with trunk diameters of greater than $30 \mathrm{~cm}$. An equal number of trees of either sex in each group were chosen: 10 trees in each group and, in total, 20 male and 20 female trees. The sampling was performed in summer-time.

Four soil samples were taken of up to $30 \mathrm{~cm}$ in depth, when it was possible, around each tree: two close to the trunk, and two far from the trunk, taken in both directions, north (N) and south (S). The sampling points close to the trunk and under the influence of the tree canopy and the trunk were denoted by N-I and S-I, and the others far from the trunk and without the influence of the canopy or the tree were denoted by N-II and S-II. Finally, a total of 160 soil samples (40 trees $\times 4$ samples per tree) were collected, as cores of $3 \mathrm{~kg}$ for each sample.

Additionally, and in order to characterise SOM, an analysis of the humus fractions was performed. For this purpose, two kinds of soil profile were selected. One of these is denoted by Profile 1, which consists of the sampling profiles of those soils located close to the largest tree trunks, and the other is Profile 2, which corresponds to the profiles in the sampling points located far from the smallest tree trunks. In each profile, soil samples were taken at different depths, given the characteristics of the soils in each case. The ranges of the depths for Profile 1 were $0-10 \mathrm{~cm}, 10-20 \mathrm{~cm}$, and $20-30 \mathrm{~cm}$, and the ranges for Profile 2 were $0-7 \mathrm{~cm}, 7-12 \mathrm{~cm}$, and $12-15 \mathrm{~cm}$. 


\subsection{Soil Preparation and Analyses}

All of the soil samples were dried $\left(35-40^{\circ} \mathrm{C}\right)$ and sieved through a $2 \mathrm{~mm}$ sieve. The fraction greater than $2 \mathrm{~mm}$ corresponded to the gravel content, which was determined gravimetrically and is shown in Table 2 as the percentage relative to the total soil sample. The fraction of soil smaller than $2 \mathrm{~mm}$ was used for determining the percentage of granulometric fractions and selected soil properties.

Table 2. Gravels (g/100 $\mathrm{g}$ of the unsieved soil), $\mathrm{pH}, \mathrm{CO}_{3}{ }^{-2}(\mathrm{~g} / 100 \mathrm{~g}$ soil) and total organic carbon (TOC; $g / 100 \mathrm{~g}$ soil) of the soil samples taken at a depth of $7 \mathrm{~cm}$ and considered for the two sampling directions north and south, the size of the trunk (A, B, C and D), and the near/far proximity to the trunk (I and II).

\begin{tabular}{cccccc}
\hline Parameter & Sample & $\mathbf{A}(\boldsymbol{d}<\mathbf{1 0})$ & $\mathbf{B}(\mathbf{1 0}<\boldsymbol{d}<\mathbf{2 0})$ & $\mathbf{C}(\mathbf{2 0}<\boldsymbol{d}<\mathbf{3 0})$ & $\mathbf{D}(\boldsymbol{d}>\mathbf{3 0})$ \\
\hline \multirow{3}{*}{$\mathrm{pH}$} & north-I & $7.93 \pm 0.25^{1}$ & $7.77 \pm 0.26$ & $7.54 \pm 0.35$ & $7.18 \pm 0.28$ \\
& south-I & $7.70 \pm 0.35$ & $7.81 \pm 0.29$ & $7.51 \pm 0.38$ & $7.60 \pm 0.58$ \\
& north-II & $7.81 \pm 0.30$ & $7.71 \pm 0.20$ & $7.56 \pm 0.28$ & $7.69 \pm 0.48$ \\
& south-II & $7.70 \pm 0.23$ & $7.76 \pm 0.19$ & $7.95 \pm 0.45$ & $7.50 \pm 0.14$ \\
\hline \multirow{2}{*}{ Gravels $(\%)$} & north-I & $23 \pm 5$ & $31 \pm 6$ & $23 \pm 4$ & $25 \pm 2$ \\
& south-I & $26 \pm 3$ & $28 \pm 10$ & $23 \pm 5$ & $22 \pm 2$ \\
& north-II & $20 \pm 2$ & $34 \pm 4$ & $27 \pm 4$ & $28 \pm 2$ \\
& south-II & $19 \pm 3$ & $28 \pm 3$ & $27 \pm 6$ & $28 \pm 4$ \\
\hline \multirow{3}{*}{$\mathrm{CO}_{3}{ }^{-2}(\%)$} & north-I & $0.42 \pm 0.06$ & $1.52 \pm 0.52$ & $2.21 \pm 0.55$ & $0.70 \pm 0.15$ \\
& south-I & $1.25 \pm 0.04$ & $2.50 \pm 0.43$ & $2.80 \pm 0.25$ & $0.90 \pm 0.01$ \\
& north-II & $1.82 \pm 0.06$ & $2.50 \pm 0.68$ & $2.80 \pm 0.59$ & $0.92 \pm 0.03$ \\
& south-II & $2.00 \pm 0.05$ & $2.42 \pm 0.12$ & $1.20 \pm 0.22$ & $0.81 \pm 0.04$ \\
\hline \multirow{2}{*}{ TOC $(\%)^{*}$} & north-I & $1.46 \pm 0.53 \mathrm{a} *$ & $2.58 \pm 0.86 \mathrm{~b}$ & $2.50 \pm 0.81 \mathrm{~b}$ & $3.60 \pm 0.96 \mathrm{c}$ \\
& south-I & $1.44 \pm 0.37 \mathrm{a}$ & $2.21 \pm 0.58 \mathrm{~b}$ & $2.28 \pm 1.23 \mathrm{~b}$ & $3.30 \pm 1.08 \mathrm{c}$ \\
& north-II & $1.12 \pm 0.26 \mathrm{~d}$ & $1.56 \pm 0.38 \mathrm{e}$ & $1.82 \pm 0.71 \mathrm{e}$ & $2.08 \pm 0.70 \mathrm{ab}$ \\
& south-II & $1.43 \pm 0.33 \mathrm{~d}$ & $1.60 \pm 0.46 \mathrm{e}$ & $1.70 \pm 0.75 \mathrm{e}$ & $2.07 \pm 0.80 \mathrm{ab}$ \\
\hline
\end{tabular}

${ }^{1}$ Mean values and standard deviations. * Significant statistical differences $(p \leq 0.05)$ only for TOC with different letters.

Silt, sand, and clay percentages were determined by a discontinuous sedimentation process based on the densimeter method. The $\mathrm{pH}$ was measured potentiometrically using a solution of soil/water $(1: 2.5 w / v)$. The total organic carbon (TOC) was determined following the method of Walkley and Black [40]. The percentage of $\mathrm{CO}_{3}{ }^{-2}$ content was measured according to Nelson [41], using a calcimeter. Total nitrogen was determined with a Heraeus V-Analyser, model Macro N, (Labexchange, Burladingen, Germany).

Additionally, two parameters, $T O C_{\text {int }}$ and $T O C_{\text {ext }}$, associated to the positions close and far to the trunk, respectively, were calculated as follows:

$$
T O C_{i n t}=\frac{1}{2}\left(T O C_{N(I)}+T O C_{S(I)}\right)
$$

and

$$
\mathrm{TOC}_{\text {ext }}=\frac{1}{2}\left(\mathrm{TOC}_{\mathrm{N}(I I)}+\mathrm{TOC}_{S(I I)}\right)
$$

where $T O C_{N(I)}$ and $T O C_{S(I)}$ were the TOC in the north and the south in the proximity of the trunk, and $T O C_{N(I I)}$ and $T O C_{S(I I)}$ were the TOC referring to the north and south far from the trunk.

\subsection{Soil Organic Carbon Fractions}

Humic substances can be operationally classified into three separate fractions defined in terms of their solubility properties [42]. Laboratory procedures attempt to divide the fractions into the subfractions of humic acids, fulvic acids and humins. Humic acids are extrated from soils with alkaline 
solutions and turn into insoluble precipitates after acidification. Fulvic acids are yellowish in colour and are soluble in both acid and alkaline solutions. Humins are insoluble in acid or alkaline solutions.

For the analysis of the humus, $50 \mathrm{~g}$ of soil of each sample, previously sieved, were used for the isolation of their fractions. Figure 2 describes the procedure proposed by Duchaufour and Jacquin [42] that was followed. The first step involved a physical separation of the soil with a mix of bromophenol and ethanol (density of $1.6 \mathrm{~g} / \mathrm{mL}$ ), for which the floating particle fraction was denoted by the soil light fraction (SLF) and the rest was denoted by the soil heavy fraction (SHF), which was used for the isolation of the humus fractions following a chemical process. The chemical process began with the separation of the soil soluble fraction (SSF) using deionised water at $20^{\circ} \mathrm{C}$. After this, the insoluble fraction was dissolved in a solution of $\mathrm{Na}_{4} \mathrm{P}_{2} \mathrm{O}_{7}(0.1 \mathrm{~N})$ in $\mathrm{Na}_{2} \mathrm{SO}_{4}(5 \%)$ fixed at $\mathrm{pH} 7.0$ and was centrifuged at $5000 \mathrm{rpm}$. The extract was taken as the total humic fraction (THF-1). For one side, the liquid was acidified down to $\mathrm{pH} 2.0$ and centrifugated at $5000 \mathrm{rpm}$, to obtain a yellowish supernatant solution containing the fulvic acids fraction (FA1) and a precipitate of humic acids (HA1). Residue 1 was extracted with a mixture of $\mathrm{Na}_{4} \mathrm{P}_{2} \mathrm{O}_{7}(0.1 \mathrm{~N})$ and $\mathrm{NaOH}(0.1 \mathrm{~N})$ regulated at $\mathrm{pH} 12.0$; from this extraction, a new THF (THF-2) was isolated and separated from the THF. The total humic extract was acidified with $\mathrm{HCl}$ down to $\mathrm{pH}$ 2.0, and was then centrifuged. Again, a supernatant liquid containing the fulvic acids fraction (FA2) and a fraction corresponding to humic acids (HA2) was obtained. The organic $C$ in the fractions was measured using a total organic carbon analyser (Leco CHN-2000, St. Joseph, MI, USA).

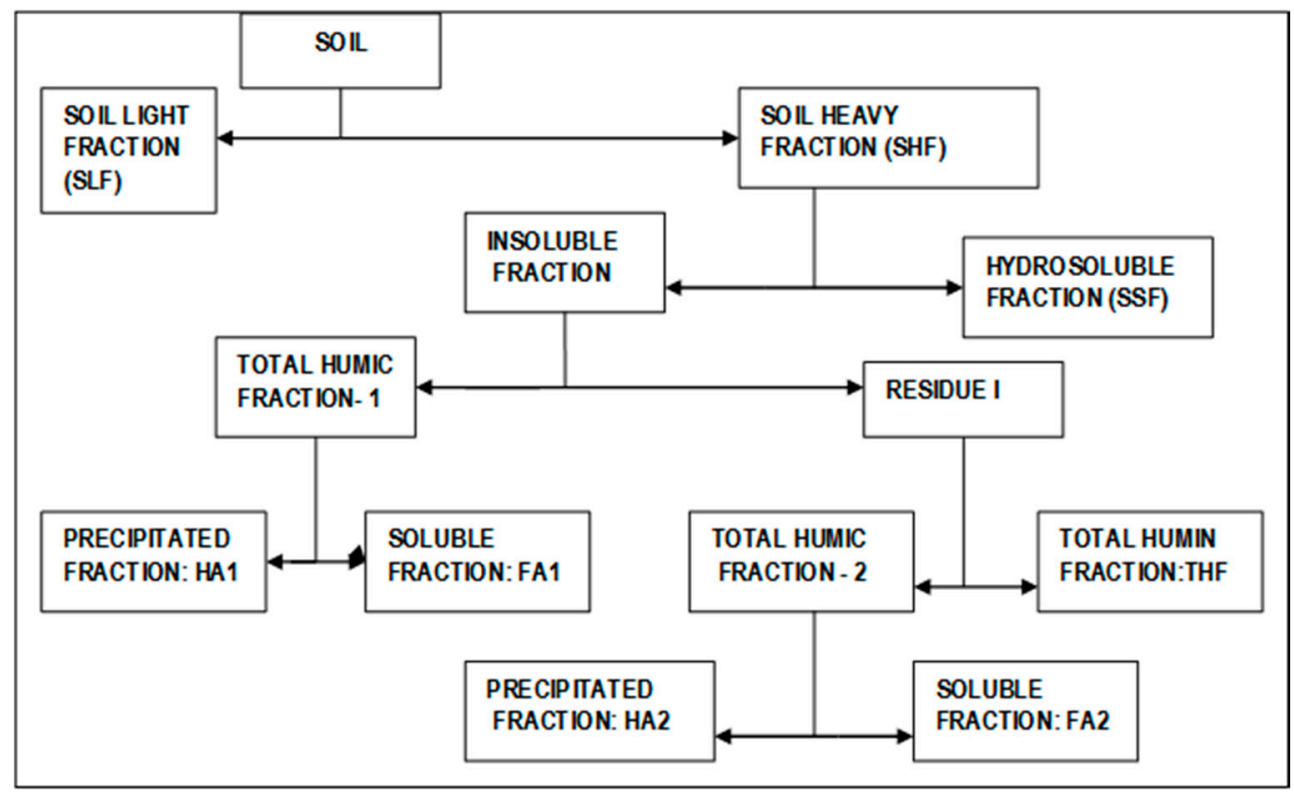

Figure 2. Flowchart showing the experimental process following the humus fraction separation.

In order to estimate the grade of stabilisation considering different organic fractions, some parameters can be defined and calculated. The ratio between the total humic acid (HA) and total fulvic acid $(F A)$, denoted by $(H A / F A)$, is the index of polymerisation, which allows one to study the grade of stabilisation of the organic matter [43]. Additionally, the degree of humification $(D H)$ is used in this work as a tool for comparing the composition of organic matter in different horizons. The $D H$ parameter is defined in different ways in different studies, but in the present work the following expression [43] was used:

$$
D H=(F A+H A) / S H F
$$




\subsection{Statistical Analysis}

The statistical method used was an analysis of variance (ANOVA), to determine the existence or absence of significant differences within two and four groups of experimental results, which, in this work, were defined by several properties. The analysis of the influence of several vegetation factors (sex, orientation, diameter of the trunk, and proximity to the trunk) on physical and chemical characteristics, as well as organic $C$, was performed through one-way ANOVA. The main effects were considered to be significant at the $p<0.05$ level. The mean separation was conducted using the Fisher's least significant difference (LSD) method. The data reported in the tables are the mean values and the precision, expressed as the standard deviation. The software SPSS 15.0 (SPSS Inc., Chicago, IL, USA) was used for the statistical analyses.

\section{Results}

\subsection{Soil Properties}

The values of $\mathrm{pH}$, gravels, $\mathrm{CO}_{3}{ }^{-2}$, and TOC for the soil samples are summarised in Table 2 . These data correspond to the sampling points according to the orientation (north or south), proximity to the tree (close or far), and size of the tree truck (A, B, C or D group classification).

The $\mathrm{pH}$ values ranged from 7.18 to 7.95 , and the mean $\mathrm{pH}$ value was similar to that found by other authors [31,44]: the $\mathrm{pH}$ under the J. thurifera canopy was found to always be above 7.0. The carbonate content was not regularly distributed given the geomorphological structures, the highest value being $2.80 \%$. The high proportion of gravels, which was up to $34 \%$, reflects the erosive processes that take place in this area. The TOC concentration ranged between $1.12 \%$ and $3.60 \%$, and these values were similar to those reported by other authors [35]. From these data, it is possible to see that the TOC was higher in the samples of soils taken for the group D trees (diameter of the trunk larger than $30 \mathrm{~cm}$ ) than those from group A trees (diameter of the trunk less than $10 \mathrm{~cm}$ ).

For a better analysis of the influence of the vegetation on the properties, a statistical analysis was performed. First, an ANOVA of $\mathrm{pH}$, gravels, carbonate content, and TOC with sex, orientation, proximity to the trunk, and size of the trunk was carried out. The results show that there was no significant effect of sex, orientation, proximity to the trunk, or size of the trunk on $\mathrm{pH}$, gravels, and carbonate content. Additionally, there was no significant effect of sex and of orientation on the TOC. The degree of significance of the differences between the two groups for the TOC of male and female trees was found to be 0.596 , and for the north and south orientations, this was 0.185 ; in these two cases, both values were higher than 0.05 . However, the TOC distribution had a dependence with the other two variables analysed in this study, the proximity to the trunk and the size of the trunk, at the $p \leq 0.05$ level. In Figure 3, the results of the Fisher LSD method are shown. The mean values for the TOC close to and far from the trunk were $2.44 \pm 0.11$ and $1.67 \pm 0.06$, respectively. The mean values for the TOC according to the size of the trunk were $1.36 \pm 0.10,1.99 \pm 0.21,2.07 \pm 0.23$, and $2.80 \pm 0.31$ for the $\mathrm{A}$, $\mathrm{B}, \mathrm{C}$, and D groups.

The contribution of every group of trees to the TOC of the area under study is shown in Table 3. Taking into account the tree density, denoted by N-tree/ha, Table 3 shows that most of the trees in the forest are those with a trunk diameter of between 10 and $20 \mathrm{~cm}(51.7 \%)$, followed by trees with a diameter of $20-30 \mathrm{~cm}(24.9 \%)$. However, the table shows that the mean value of the TOC measured in the soil samples taken close to group $\mathrm{D}$ trees $\left(\mathrm{TOC}_{\mathrm{int}}=3.45 \%\right)$ was found to be 3 times greater than that obtained from the samples taken far from the group A trees ( $\mathrm{TOC}_{\mathrm{ext}}=1.28 \%$ ). Taking into account only the percentage of $C$ in the sampling points close to the tree and under the canopy $\left(\mathrm{TOC}_{\mathrm{int}}\right)$, and the percentage of trees per hectare in each group, the contribution of every group of trees to the TOC could be estimated. 

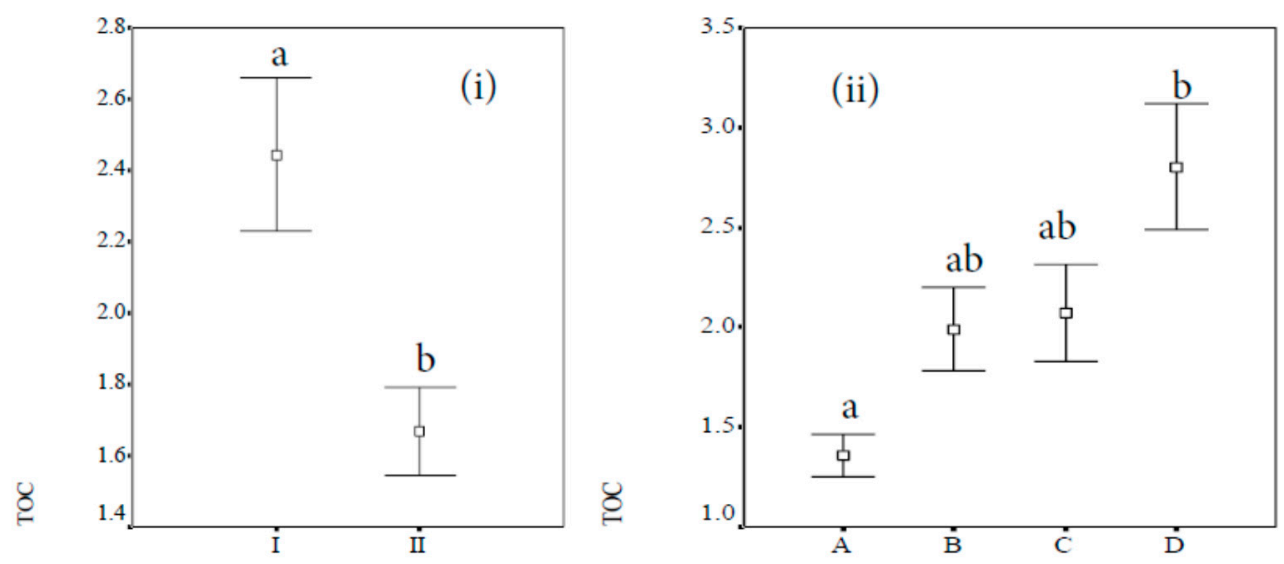

Figure 3. Analysis of the influence of the protection (I) and lack of protection (II) of the canopy (i) and the trunk diameter (ii) on the soil total organic carbon (TOC) concentration (\%). The represented data are the mean values and confidence intervals (95\%). Bars with the same letters are not significantly different $(p<0.05)$.

Table 3. Total organic carbon (TOC) concentration (\%) in soils under and soils without the influence of the canopy $\left(\mathrm{TOC}_{\mathrm{int}}\right.$, and $\mathrm{TOC}_{\mathrm{ext}}$ respectively) for the four groups of trees.

\begin{tabular}{cccccc}
\hline Group of Trees & TOC $_{\text {int }} /$ Tree $^{\mathbf{1}}$ & TOC $_{\text {ext }} /$ Tree $^{\mathbf{1}}$ & N-Trees/ha & \% Trees/ha & TOC/ha $^{\mathbf{2}}$ \\
\hline $\mathrm{A}(d<10 \mathrm{~cm})$ & $1.45 \mathrm{a}$ & $1.28 \mathrm{ab}$ & 31 & 14.8 & 9.0 \\
$\mathrm{~B}(10 \mathrm{~cm}<d<20 \mathrm{~cm})$ & $2.40 \mathrm{~b}$ & $1.58 \mathrm{~d}$ & 108 & 51.7 & 52.8 \\
$\mathrm{C}(20 \mathrm{~cm}<d<30 \mathrm{~cm})$ & $2.39 \mathrm{~b}$ & $1.76 \mathrm{~d}$ & 52 & 24.9 & 25.4 \\
$\mathrm{D}(d>30 \mathrm{~cm})$ & $3.45 \mathrm{c}$ & $2.08 \mathrm{dc}$ & 18 & 8.6 & 12.6 \\
\hline
\end{tabular}

${ }^{1}$ Evaluated with the data from Table $2 .{ }^{2}$ Contribution to the total given the number of trees. Values with different letters are significantly different $(p<0.05)$.

The data of Table 3 shows that the main contribution to the $C$ concentration in the forest soil corresponded to the trees with a medium-sized diameter (group B and C trees), which had a contribution of almost $80 \%$ to the total $C$ concentration. However, each tree group did not have the same contribution to the TOC, given that this depends on the size of the trunk: a group D tree contributed $35 \%$, a group A tree contributed $15 \%$, and group C and D trees contributed $25 \%$ each. The data show that with larger sizes of the trees-that is, a greater age-the TOC is increased.

The results of the analysis of the soils taken from the two sets of selected profiles of this forest are shown in Table 4. The vertical distribution of the silt, sand, clay, $\mathrm{pH}$, carbonates, TOC, and the ratio between the $\mathrm{C}$ and nitrogen $(\mathrm{N})$ concentration $(\mathrm{C} / \mathrm{N})$ in every soil profile can be observed, where mean values and their standard deviation are reported; these were obtained from the statistical analyses of the experimental data. From these results, it is possible to conclude that no vertical variation for the $\mathrm{pH}$ value and clay content is observed in any of the two profiles. However, the inorganic $\mathrm{C}$ as $\mathrm{CO}_{3}{ }^{-2}$ and silt contents increased with depth, and sand content decreased with depth. The TOC and the C/N ratio are higher in Profile 1 than Profile 2, and they clearly decrease with depth in Profile 2. Given the higher values of the $\mathrm{C} / \mathrm{N}$ ratio [45] in Profile 1 than in Profile 2, a higher microbial activity was expected in the soil of Profile 2. That means that a faster emission of $\mathrm{CO}_{2}$ would be produced in the soils that were without the protection of the canopy and were far from the tree trunk. 
Table 4. Mean values and standard deviations for $\mathrm{C} / \mathrm{N}$ ratio, $\mathrm{pH}$ and percentages (g/100g soil) of total organic carbon (TOC), carbonates, clay, silt, and sand at several depths (cm) in soil Profiles 1 and 2.

\begin{tabular}{|c|c|c|c|c|c|c|c|c|}
\hline Soil & Depth & $\mathrm{CO}_{3}{ }^{-2}$ & $\mathrm{pH}$ & TOC & $\mathrm{C} / \mathrm{N}$ & Clay & Silt & Sand \\
\hline \multirow{3}{*}{ Profile 1} & $0-10$ & $0.42 \pm 0.09 a$ & $8.12 \pm 0.97 a$ & $3.94 \pm 0.29 a$ & $5.96 \pm 0.41 \mathrm{a}$ & $16 \pm 4 a$ & $19 \pm 6 a$ & $65 \pm 16 a$ \\
\hline & $10-20$ & $1.22 \pm 0.28 \mathrm{~b}$ & $7.67 \pm 1.15 a$ & $2.93 \pm 0.18 b$ & $5.79 \pm 0.23 b$ & $32 \pm 10 a$ & $40 \pm 12 b$ & $28 \pm 2 b$ \\
\hline & $20-30$ & $1.62 \pm 0.30 \mathrm{ab}$ & $7.65 \pm 1.45 \mathrm{a}$ & $2.73 \pm 0.32 c$ & $6.22 \pm 0.35 c$ & $20 \pm 5 \mathrm{a}$ & $52 \pm 14 c$ & $20 \pm 5 c$ \\
\hline \multirow{3}{*}{ Profile 2} & $0-7$ & $0.19 \pm 0.07 \mathrm{a}$ & $8.30 \pm 1.31 \mathrm{a}$ & $2.16 \pm 0.36 \mathrm{ab}$ & $3.77 \pm 0.18 \mathrm{ab}$ & $20 \pm 5 a$ & $35 \pm 12 \mathrm{a}$ & $45 \pm 10 \mathrm{ab}$ \\
\hline & $7-12$ & $1.95 \pm 0.47 c$ & $8.06 \pm 2.11 \mathrm{a}$ & $1.81 \pm 0.31 \mathrm{bc}$ & $3.54 \pm 0.20 \mathrm{bc}$ & $22 \pm 7 a$ & $48 \pm 10 \mathrm{a}$ & $30 \pm 10 b$ \\
\hline & $12-15$ & $2.28 \pm 0.65 \mathrm{~d}$ & $8.27 \pm 1.53 \mathrm{a}$ & $1.38 \pm 0.25 \mathrm{~d}$ & $3.17 \pm 0.11 \mathrm{~d}$ & $19 \pm 5 a$ & $53 \pm 20 a$ & $28 \pm 9 b$ \\
\hline
\end{tabular}

Values with different letters in columns are significantly different $(p<0.05)$.

The TOC in the soil of Profile 1 (at any depth) was greater than that in Profile 2, and these C contents decreased with depth in both soils. The TOC was greater in Profile 1 than in Profile 2 because of the size of the tree and the proximity to the trunk. In the studied area, the $\mathrm{C}$ concentration in the upper level of the soil can be explained by taking the litter into account. The large TOC accumulation takes place in the areas under the canopy, and it is even more in proportion with the trees with the largest diameters; this behaviour was also found by Gauquelin and Dagnac [31].

\subsection{Study of Organic Carbon Fractions}

The data corresponding to the SOC fractions in two different soil profiles, Profile 1 (close to the trunk) and Profile 2 (far from the trunk) are collected in Tables 5 and 6, respectively, where organic $C$ is given as a percentage ( $\mathrm{g} / 100 \mathrm{~g}$ of soil). The analysis of the composition and stability of the organic matter in the soil for this forest has been performed by comparing the data reported in both tables.

Table 5. Organic C fractions (in g/100 g soil) in soil samples at different depths (range) in Profile 1.

\begin{tabular}{cccc}
\hline Samples in Profile 1 & $\mathbf{0 - 1 0} \mathbf{~ c m}$ & $\mathbf{1 0 - 2 0} \mathbf{~ c m}$ & $\mathbf{2 0 - 3 0} \mathbf{~ c m}$ \\
\hline Soil Total Organic Carbon (TOC) & $3.94 \pm 0.29^{1} \mathrm{a}$ & $2.93 \pm 0.18 \mathrm{~b}$ & $2.73 \pm 0.32 \mathrm{~b}$ \\
Soil Light Fraction (SLF) & $0.85 \pm 0.07 \mathrm{a}$ & $0.41 \pm 0.06 \mathrm{~b}$ & $0.45 \pm 0.07 \mathrm{~b}$ \\
Soil Heavy Fraction (SHF) & $3.09 \pm 0.26 \mathrm{a}$ & $2.52 \pm 0.32 \mathrm{~b}$ & $2.28 \pm 0.36 \mathrm{c}$ \\
Fulvic Acid-1 (FA1) & $0.17 \pm 0.01 \mathrm{a}$ & $0.16 \pm 0.02 \mathrm{a}$ & $0.20 \pm 0.02 \mathrm{~b}$ \\
Fulvic Acid-2 (FA2) & $0.07 \pm 0.06 \mathrm{a}$ & $0.09 \pm 0.01 \mathrm{a}$ & $0.05 \pm 0.01 \mathrm{a}$ \\
Total Fulvic Acid (FA = FA1 + FA2) & 0.24 & 0.25 & 0.25 \\
Humic Acid-1 (HA1) & $0.16 \pm 0.01 \mathrm{a}$ & $0.34 \pm 0.02 \mathrm{~b}$ & $0.22 \pm 0.04 \mathrm{c}$ \\
Humic Acid-2 (HA2) & $0.07 \pm 0.01 \mathrm{a}$ & 0.45 & $0.08 \pm 0.01 \mathrm{c}$ \\
Total Humic Acids (HA = HA1 + HA2) & 0.23 & 0.70 & 0.30 \\
Total Fulvic and Humic Acids (FA + HA) & 0.47 & $1.83 \pm 0.23 \mathrm{~b}$ & 0.55 \\
Total Humin (THF) & $2.62 \pm 0.42 \mathrm{a}$ & 1.80 & $1.74 \pm 0.26 \mathrm{c}$ \\
HA/FA & 0.98 & 0.28 & 1.20 \\
Degree of Humification (DH) & 0.15 & 0.24 & 0.015 \\
\hline
\end{tabular}

${ }^{1}$ Mean values and standard deviations. Values with the same letter for the same fraction at different depths are not significantly different $(p<0.05)$.

The C concentration in the SHF, which was greater than that for the SLF, was also greater in Profile 1 than in Profile 2. The SLF was also higher in Profile 1 than in Profile 2, and it was related with the free organic matter, which refers to fresh and non-degraded matter. However, no value is shown in Table 5 or Table 6 for the SSF, given that it was considered negligible in both soil profiles. Additionally, there is evidence of a higher humus content in soil Profile 1 than in Profile 2, given the total humin, FA, and HA reported in Tables 5 and 6.

For a better view, the $\mathrm{C}$ concentration in the different organic fractions for each soil are also shown graphically in Figure 4. The humus composition can be easily compared if the amount of the different humic fractions is calculated as a percentage of the TOC, which is shown by different lengths in the columns. In both soils, the greatest contribution to the humus was due to the humin (THF; in green), which was at least $60 \%$ of the total humus (see Figure 4). The humin content in Profile 1 was almost constant with depth, but it increased in Profile 2. The high proportion of humins in both profiles shows that a high content of humified organic matter is accumulated by this forest. The humification process 
implies the formation of humus, that is, the transformation of organic compounds into substances with resistance to biodegradation and mineralisation [46-48].

Table 6. Organic C fractions (in g/100 g soil) in soil samples at different depths (range) in Profile 2.

\begin{tabular}{cccc}
\hline Samples in Profile 2 & $\mathbf{0 - 7} \mathbf{~ c m}$ & $\mathbf{7 - 1 2} \mathbf{~ c m}$ & $\mathbf{1 2 - 1 5} \mathbf{~ c m}$ \\
\hline Soil Total Organic Carbon (TOC) & $2.16 \pm 0.36^{1} \mathrm{a}$ & $1.81 \pm 0.31 \mathrm{~b}$ & $1.38 \pm 0.25 \mathrm{c}$ \\
Soil Light Fraction (SLF) & $0.45 \pm 0.08 \mathrm{a}$ & $0.15 \pm 0.02 \mathrm{~b}$ & $0.01 \pm 0.01 \mathrm{c}$ \\
Soil Heavy Fraction (SHF) & $1.71 \pm 0.20 \mathrm{a}$ & $1.66 \pm 0.14 \mathrm{a}$ & $1.38 \pm 0.09 \mathrm{~b}$ \\
Fulvic Acid-1 (FA1) & $0.13 \pm 0.01 \mathrm{a}$ & $0.04 \pm 0.01 \mathrm{~b}$ & $0.06 \pm 0.02 \mathrm{~b}$ \\
Fulvic Acid-2 (FA2) & $0.06 \pm 0.05 \mathrm{a}$ & $0.08 \pm 0.07 \mathrm{a}$ & $0.04 \pm 0.01 \mathrm{a}$ \\
Total Fulvic Acid (FA = FA1 + FA2) & 0.19 & 0.12 & 0.10 \\
Humic Acid-1 (HA1) & $0.11 \pm 0.02 \mathrm{a}$ & $0.05 \pm 0.01 \mathrm{~b}$ & $0.10 \pm 0.04 \mathrm{a}$ \\
Humic Acid-2 (HA2) & $0.02 \pm 0.02 \mathrm{a}$ & $0.13 \pm 0.02 \mathrm{~b}$ & $0.05 \pm 0.02 \mathrm{c}$ \\
Total Humic Acids (HA = HA1 + HA2) & 0.13 & 0.18 & 0.15 \\
Total Fulvic and Humic Acids (FA + HA) & 0.32 & 0.30 & 0.25 \\
Total Humin (THF) & $1.37 \pm 0.43 \mathrm{a}$ & $1.36 \pm 0.51 \mathrm{a}$ & $1.11 \pm 0.42 \mathrm{~b}$ \\
HA/FA & 0.68 & 1.50 & 1.50 \\
Degree of Humification (DH) & 0.19 & 0.18 & 0.18 \\
\hline
\end{tabular}

${ }^{1}$ Mean values and standard deviations. Values with the same letter for the same fraction at different depths are not significantly different $(p<0.05)$.

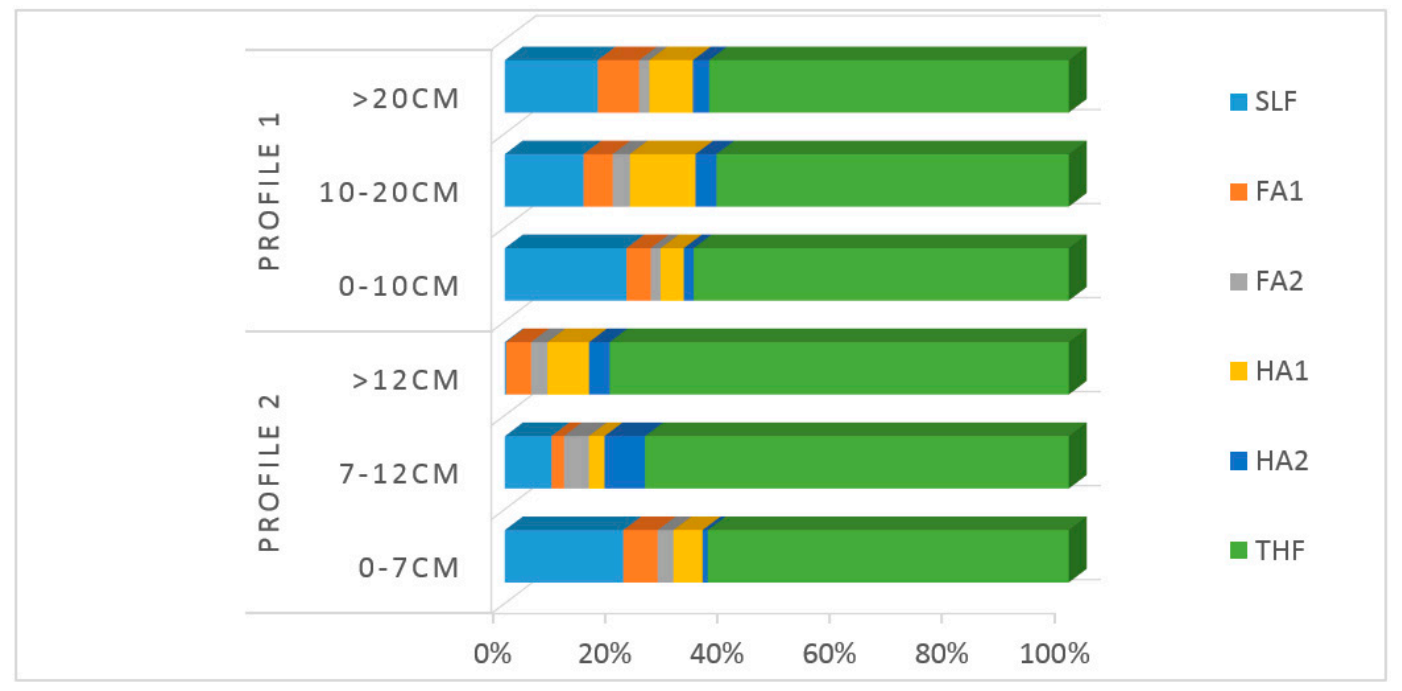

Figure 4. Organic $C$ (percentages referenced to the total organic carbon-TOC) at different depths of the profile in the humus fractions.

Additionally, there are other parameters that allow for the characterisation of soil humus and that determine how it was formed, by the ratio (HA/FA) and the index DH $[25,49,50]$, which are given for both profiles in Tables 5 and 6 . The index HA/FA was lower than the unit in the first centimetres of both profiles and higher than the unit for deeper samples. Given that the HA is the result of the transformation of the FA, the data show that the polymerisation degree increased with depth. The other parameter $(\mathrm{DH})$ indicates how the process of humification, which is a function of biological activity, progresses. The smallest value for the DH was found for the upper level of Profile 1. In Profile 1, the $\mathrm{DH}$ values show that the humification processes were more important in deeper soils, although not in the upper level of the profile, for which the input of the fresh plant material from the litter under the canopy causes an inhibition of the humification processes. In Profile 2, the value of the DH was 0.18 and it was independent of depth, which means that the humification processes were the same along the profile. 


\section{Discussion}

From the analysis that has been carried out, we can conclude that there is a clear influence of the tree on the accumulation of $C$ in soil. The thickness of the trunk and the protection of the canopy are factors to take into account in order to determine the variability of the concentration and composition of the humus, but neither the sex of the tree nor the north-south orientation has an influence. Quantitatively, higher contents of $C$ exist under the canopy of the tree, as well as in the proximity of larger trees. The litter on the soil is the main reason for this, given that it increased with the size of the trunk, was non-existent far from the trunk and out from under the canopy, and was also almost negligible in the proximity of the smallest trees. The litter contributes fresh organic matter but with a protection that improves the humification processes in the soil. Thus, older trees have a higher organic $\mathrm{C}$ concentration.

The analysis of the vertical distribution of the TOC shows that the upper layer has a higher concentration and that it decreases with depth. The gradients of decreasing TOC along Profile 1 and Profile 2 were $0.04 \%$ and $0.05 \%$ TOC/cm, respectively, which means that there is an influence of the tree in the depth distribution of the organic $\mathrm{C}$. The analysis of the $\mathrm{C} / \mathrm{N}$ along the profiles shows that the mineralisation process is slower in soils under the protection of the canopy, and, by the analysis of the litter, is slower than in soils without the influence of the tree. Thus, both analyses suggest the importance of the vegetation in the soil processes. Soils under the influence of the trees, close to the trunk and under the canopy, and particularly for trees with a larger trunk, present higher concentrations of organic $C$, and its variation with depth is less than for soils far from the influence of trees. The value of the TOC from soil samples taken close to group D trees $\left(\mathrm{TOC}_{\mathrm{int}}=3.45 \%\right)$ was found to be similar to that reported for a similar forest by González and Candás [36], which was $3.760 \%$.

Apart from the mineralisation process, the other organic matter process is humification, and this takes place in a different way at different depths. The vertical distribution of the $C$ fractions shows the results of this humification process. Qualitatively, the organic matter in the samples taken from sites close to the trunk and under the canopy had a higher stability, given that the humin fraction was higher in these sites, at any depth. The humin fraction is associated to recalcitrant $C$, given that its compounds have a slow degradation and a high resistance to biodegradability, and, thus, it contributes to long-term C storage in soils [13]. Other parameters, such as the total content of fulvic and humic acids, support the hypothesis of the influence of the vegetation on the stabilisation of the organic matter in the soils.

Comparing the proportion of the different fractions with respect to the TOC along both profiles, the effect of the vegetation on the humification process can be discussed. The most recalcitrant fraction (humin) had no variation with depth for the soils under the influence of the tree, but in the absence of this influence, this fraction increased with depth, as mineralisation processes are important in the upper level, but less so in the deeper layers in such unforested soils. The opposite occurred, in the soil profiles under study, for the SSF, which was negligible, but this fraction was the labile C composed of compounds, such as soluble sugars and other carbohydrates, which have been shown to play a dominant role in the evolution of $\mathrm{CO}_{2}$ from soil as a result of preferential decomposition and rapid turnover [51]. Other fractions of less-humificated C (SLF) were higher in the upper layers in both profiles, where the competition with mineralisation processes in unforested soils and the influence of the litter in the soils close to the vegetation have been taken into account. Additionally, the SLF decreased very sharply in Profile 2, and the absence of litter could explain this fact. Litter is not only a source of $C$, it also has a buffer effect against extreme temperatures, as well as a protective function against water and air erosion [32].

A simple comparison with other forests can be performed. Table 7 shows the results obtained in the present study with those of a previous work, for which the same methodology was followed [52]. The data of the thurifera forests correspond to average values obtained from Profile 1 . All the values are given as the percentage of $C$ with respect to $100 \mathrm{~g}$ of soil and also refer to the TOC (in parentheses) for each fraction. Analysing the table, it is clear than the organic $\mathrm{C}$ level is higher in oak forests, 
and thurifera forests have a lower $\mathrm{C}$ content. Additionally, Table 7 shows that the organic $\mathrm{C}$ in the different fractions is lower in the thurifera forest than in oak and pine forests, given that the first soils are particularly poor in organic matter, as is usual in semi-arid soils.

Table 7. Comparative data of $\mathrm{C}$ concentration (\%) in different organic fractions for different forest soils.

\begin{tabular}{cccc}
\hline Sample Soil & Thurifera $^{\mathbf{1}}$ & Pine $^{\mathbf{2}}$ & Oak $^{\mathbf{2}}$ \\
\hline Soil Organic Carbon (SOC) & $3.20(100)^{3}$ & $10.23(100)$ & $11.80(100)$ \\
Soil Heavy Fraction (SHF) & $2.63(82.19)$ & $8.04(78.59)$ & $10.38(87.97)$ \\
Soil Light Fraction (SLF) & $0.57(17.81)$ & $2.19(21.41)$ & $1.52(12.88)$ \\
Fulvic Acid-1 (FA1) & $0.18(5.63)$ & $0.87(8.50)$ & $0.89(7.54)$ \\
Fulvic Acid-2 (FA2) & $0.07(2.19)$ & $0.92(8.99)$ & $0.92(7.80)$ \\
Total Fulvic Acid (FA) & $0.25(7.81)$ & $1.79(17.50)$ & $1.81(15.34)$ \\
Humic Acid-1 (HA1) & $0.24(7.50)$ & $0.45(4.40)$ & $0.62(5.25)$ \\
Humic Acid-2 (HA2) & $0.09(2.81)$ & $2.38(23.26)$ & $3.29(27.88)$ \\
Total Humic Acids (HA) & $0.33(10.31)$ & $2.83(27.66)$ & $3.91(33.14)$ \\
Total Fulvic and Humic Acids & $0.58(18.13)$ & $4.83(47.21)$ & $5.89(49.92)$ \\
Total Humin & $2.06(64.38)$ & $3.47(33.92)$ & $4.66(39.49)$ \\
HA/FA & 1.32 & 1.58 & 2.16 \\
Degree of Humification (DH) & 0.22 & 0.60 & 0.57
\end{tabular}

${ }^{1}$ The values are the average of those reported at different depths in Table 5 for Profile 1. ${ }^{2}$ Data taken from [43].

${ }^{3}$ In parenthesis is the value (\%) in reference to the total organic carbon (TOC).

An interesting point for analysis is the capacity of the different forests for the stabilisation of the organic $\mathrm{C}$. For this purpose, the data referring to the TOC are very useful. These data show that the proportion of the humin (with respect to the TOC) in the thurifera forest was considerably higher than for the other two forests (pine and oak): $64 \%$ versus 34\% and 39\%. This fact confirms that the soil in J. thurifera forests presents a higher proportion of organic matter resistant to degradation and recalcitrant organic $C$ than in oak and pine forests. Furthermore, the contents of the total fulvic and humic acids in the J. thurifera forest were lower than those found in pine and oak forests (see Table 7). However, if humic and fulvic acids are compared with humin, a proportion of humin 3.6 times higher than for acids is found in the thurifera soils, versus the estimated 0.7 and 0.8 for pine and oak forests, respectively. Thus, taking into account that humin is organic matter that is more humificated than the fulvic and humic acids, the stabilisation of the organic matter in the oak and pine forests was lower than that for the J. thurifera forest. Thus, the thurifera forest could have a better capacity for the stabilisation of its low SOC than the pine and oak forests presented here. This fact shows that the SOM of $J$. thurifera forest has a reduced biodegradability if it is compared with pine and oak forests, and this characteristic can be explained in terms of the vegetation and the type of microorganisms responsible for the humification process, as well as by the age of the forest and its history.

\section{Conclusions}

We can conclude that the studied J. thurifera forest does not have a large amount of $C$ if it is compared with the other forests mentioned in this work; however, its organic matter is more stable than those for the oak and pine forests of a previous work [52]. The loss of $C$ in the soil is due to degradation processes and it is increasing with global warming, as was pointed out in other works [5]. The soil can be considered a large $\mathrm{C}$ sink of the forest ecosystem, according to one author [53], but we conclude that this fact depends on the amount of organic $C$ storage and its grade of resistance to biodegradability. The efficiency of a $C$ sink is given by the balance between its capacity for $C$ sequestration and for the conservation and the reduction of its natural loss. Consequently, in agreement with De Deyn et al. [54], the efficiency of the $\mathrm{C}$ sequestration by the soil depends strongly on the age of the forest, as is the case for the semi-arid soil of the studied J. thurifera forest. Thus, the J. thurifera forest soils should be regarded as an active $C$ sink, and indeed, an ideal $C$ sink, given their organic matter stability. 
The information obtained in the present work may be very useful for studies on optimising land management in Spanish mountain ecosystems, if an environmental perspective is adopted. The study reveals that, for ecosystems such as that presented here, vegetation destruction or inadequate substitution can change the equilibrium of the SOM and produce its irreversible degradation. This is a strong reason to support the protection of natural forests.

Acknowledgments: This work was supported by Junta de Castilla y León (projects VA094A06 and VA014A07) and MEC (project CTM2006-02249/TECNO).

Author Contributions: E.C. and A.M. conceived and designed the experiments, R.C. performed the experiments, A.M. analysed the data, and E.C. wrote the paper.

Conflicts of Interest: The authors declare no conflict of interest. The founding sponsors had no role in the design of the study; in the collection, analyses, or interpretation of data; in the writing of the manuscript; or in the decision to publish the results.

\section{References}

1. Liu, J.; Wu, F. Forest carbon sequestration subsidy and carbon tax as part of China's forestry policies. Forests 2017, 8, 58. [CrossRef]

2. Lal, R. Carbon sequestration in soil. Curr. Opin. Environ. Sustain. 2015, 15, 79-86. [CrossRef]

3. Powlson, D.S. Will soil amplify climate change? Nature 2005, 433, 204-205. [CrossRef] [PubMed]

4. Kerr, R.A. How hot will the greenhouse world be? Science 2005, 309, 100. [CrossRef] [PubMed]

5. Charro, E.; Moyano, A. Potential impact of climate change on agricultural soils simulated by Roth-C model. In Climate Variability, Modelling Tools and Agricultural Decision Making; Nova Science Publishers: Hauppauge, NY, USA, 2009; pp. 311-320.

6. Charro, E. Estimation of the potential carbon sequestration for forest soils under pinus halepensis using Roth-C. In Pine Forest: Types, Threads and Management; Nova Science Publishers: Hauppauge, NY, USA, 2012; pp. 123-138.

7. Chen, D.; Yu, M.; González, G.; Zou, X.; Gao, Q. Climate impacts on soil carbon processes along an elevation gradient in the tropical luquillo experimental. Forests 2017, 8, 90. [CrossRef]

8. Keenan, R.J. Adaptation of forests and forest management to climate change: An editorial. Forests 2012, 3, 75-82. [CrossRef]

9. Houghton, R.A. Aboveground forest biomass and the global carbon balance. Glob. Chang. Biol. 2005, 11, 945-958. [CrossRef]

10. Peichl, M.; Arain, M.A. Above- and below-ground ecosystem biomass and carbon pools in an age-sequence of temperate pine plantation forests. Agric. For. Meteorol. 2006, 140, 51-63. [CrossRef]

11. Oliver, G.R.; Pearce, S.H.; Kimberly, M.O.; Ford-Robertson, J.B.; Robertson, K.A.; Beets, P.N.; Garrett, L.G. Variation in soil carbon in pine plantations an implications for monitoring soil carbon stock in relation to land-use change and forest site management in New Zeeland. For. Ecol. Manag. 2004, 203, 283-295. [CrossRef]

12. Jabággy, E.G.; Jackson, E.B. The vertical distribution of soil organic carbon and its relation to climate and vegetation. Ecol. Appl. 2000, 10, 423-436. [CrossRef]

13. Ahmed, I.U.; Smith, A.R.; Jones, D.L.; Godbold, D.L. Tree species identity influences the vertical distribution of labile and recalcitrant carbon in a temperate deciduous forest soil. For. Ecol. Manag. 2016, 359, 352-360. [CrossRef]

14. Leuschner, C.; Wulf, M.; Bäuchler, P.; Hertel, D. Soil C and nutrient stores under Scots pine afforestations compared to ancient beech forests in the German Pleistocene: The role of tree species and forest history. For. Ecol. Manag. 2013, 310, 405-415. [CrossRef]

15. Vesterdal, L.; Schmidt, I.K.; Callesen, I.; Nilsson, L.O.; Gundersen, P. Carbon and nitrogen in forest floor and mineral soil under six common European tree species. For. Ecol. Manag. 2008, 255, 35-48. [CrossRef]

16. Klein, D.; Höllerl, S.; Blaschke, M.; Schulz, C. The Contribution of managed and unmanaged forests to climate change mitigation-A model approach at stand level for the main tree species in Bavaria. Forests 2013, 4, 43-69. [CrossRef] 
17. Luyssaert, S.; Schulze, E.D.; Börner, A.; Knohl, A.; Hessenmöller, D.; Law, B.E.; Ciais, P.; Grace, J. Old-growth forests as global carbon sinks. Nature 2008, 455, 213-215. [CrossRef] [PubMed]

18. Lal, R. Forest soils and carbon sequestration. For. Ecol. Manag. 2005, 220, 242-258. [CrossRef]

19. Sierra, C.A.; del Valle, J.I.; Orrego, S.A.; Moreno, F.H.; Harmon, M.E.; Zapata, M.; Colorado, G.J.; Herrera, M.A.; Lara, W.; Restrepo, D.E.; et al. Total carbon stocks in a tropical forest landscape of the Porce region, Colombia. For. Ecol. Manag. 2007, 243, 299-309. [CrossRef]

20. Hayes, M.H.B.; Clapp, C.E. Humic substances: Considerations of compositions, aspects of structure, and environmental influences. Soil Sci. 2001, 166, 723-737. [CrossRef]

21. Chefetez, B.; Tarchitzky, J.; Destimukh, A.P.; Hatcher, P.G.; Chen, Y. Structural characterization of soil organic matter and humic acids in particle size fractions of an agricultural soil. Soil Sci. Soc. Am. J. 2002, 66, 129-141. [CrossRef]

22. Shirshova, L.T.; Ghabbour, E.A.; Davies, G. Spectroscopic characterization of humic acid fractions isolated from soil using different extraction procedures. Geoderma 2006, 133, 204-216. [CrossRef]

23. McLauchlan, K.; Hobbie, S.E. Comparison of labile soil organic matter fractionation techniques. Soil Sci. Soc. Am. J. 2004, 68, 1616-1625. [CrossRef]

24. Maie, N.; Watanabe, A.; Kimura, M. Chemical characteristics and potential source of fulvic acids leached from the plow layer of paddy soil. Geoderma 2004, 120, 309-323. [CrossRef]

25. Dai, J.; Ran, W.; Xing, B.; Gu, M.; Wang, L. Characterization of fulvic acid fractions obtained by sequential extractions with $\mathrm{pH}$ buffers, water and ethanol from paddy soils. Geoderma 2006, 135, 284-295. [CrossRef]

26. Díaz-Pinés, E.; Rubio, A.; Van Miegroet, H.; Montes, F.; Benito, M. Does tree species composition control soil organic carbon pools in Mediterranean mountain forests? For. Ecol. Manag. 2011, 262, 1895-1904. [CrossRef]

27. Segura, C.; Jiménez, M.N.; Nieto, O.; Navarro, F.B.; Fernández-Ondoño, E. Changes in soil organic carbon over 20 years after afforestation in semiarid SE Spain. For. Ecol. Manag. 2016, 381, 268-278. [CrossRef]

28. IPCC. Climate Change 2001: Mitigation. Available online: http://www.grida.no/climate/ipcc_tar/wg3/ pdf/TAR-totaal.pdf (accessed on 1 March 1999).

29. Fang, X.; Zhang, C.; Wang, Q.; Chen, X.; Ding, J.; Karamage, F. Isolating and quantifying the effects of climate and $\mathrm{CO}_{2}$ changes (1980-2014) on the net primary productivity in arid and semiarid China. Forests 2017, 8, 60. [CrossRef]

30. Gauquelin, T.; Bertaudière, V.; Montès, N.; Badri, W.; Asmodé, J.F. Endangered stands of Thuriferous juniper in the western Mediterranean basin: Ecological status, conservation and management. Biodivers. Conserv. 1999, 8, 1479-1498. [CrossRef]

31. Gauquelin, T.; Dagnac, J. Caractéristiques édaphiques des groupements à Genévrier thurifère des Atlas marocains: Étude des niveaux superficiels des sols sous couvert et hors couvert. Ecol. Mediterr. 1988, XIV, 43-56.

32. Gauquelin, T.; Fromard, F.; Badri, W.; Dagnac, J. Apports d'éléments minéraux au sol par l'intermédiaire de la litière des pluies et des pluviolessivats dans un peuplement à genévrier thurifère (Juniperus thurifera L.) du Haut Atlas occidental (Maroc). Ann. Sci. For. 1992, 49, 391-414. [CrossRef]

33. Gauquelin, T.; Bertaudière, V.; Montès, N.; Savoie, J.M.; Badri, W. Cycle biogéochimique et hétérogénéité édaphique des groupements forestiers pré-steppiques à Genévrier thurifère du Haut Atlas de Marrakech. Maroc. Ecologie. Rev. Soc. Fr. d'Ecol. 1998, 29, 177-180.

34. Montès, N.; Bertaudière-Montes, V.; Badri, W.; Zaoui, E.H.; Gauquelin, T. Biomass and nutrient content of a semi-arid mountain ecosystem: The Juniperus thurifera L. woodland of Azzaden Valley (Morocco). For. Ecol. Manag. 2002, 166, 35-43. [CrossRef]

35. González, J.; Candas, M.A. Características de suelos bajo sabinares albares sobre material calizo. Suelo Planta 1991, 1, 425-438.

36. Gonzalez, J.; Candás, M.A. Materia orgánica en suelos de bosques sabineros, Juníperus thurífera L. Edafología 2004, 11, 119-135.

37. García-Morote, F.A.; López-Serrano, F.R.; Andrés, M.; Martínez-García, E.; Lucas-Borja, M.; Dadi, T.; Candel, D.; Wic, C. Effects of woodland maturity, vegetation cover and season on enzymatic and microbial activity in thermophilic Spanish Juniper woodlands (Juniperus thurifera L.) of southern Spain. Eur. J. Soil Sci. 2012, 63, 579-591. [CrossRef] 
38. Lahouel, N.; Benabadji, N.; Benmansour, D. Characterization of the organic matter in the formations with Juniperus phoenicea, and Pinus halepensis in the Matorrals of the Mostaganémois Littoral. Open J. Ecol. 2014, 4, 253-261. [CrossRef]

39. USDA. Soil Taxonomy: A basic system of soil Classification for making and interpreting soil surveys. In Agriculture Handbook; USDA: Washington, DC, USA, 1999; Volume 436, p. 869.

40. Walkley, A.; Black, I.A. An examination of the Degtjareff method for determining organic carbon in soils: Effect of variations in digestion conditions and of inorganic soil constituents. Soil Sci. 1934, 63, 251-263. [CrossRef]

41. Nelson, R.E. Carbonate and gypsum. In Methods of Soil Analysis—Part 2: Chemical and Microbiological Properties; Soil Science Society of America: Madison, WI, USA, 1982; Volume 5, pp. 437-474.

42. Duchaufour, P.; Jacquin, F. Comparaison des processus d'humification dans les principaux types d'humus forestiers. Bull. AFES 1975, 1, 29-36.

43. Zanelli, R.; Egli, M.; Mirabella, A.; Giaccai, D.; Fitze, P. Influence of laurophyllous species, Castanea sativa and Quercetum-Betuletum vegetation on organic matter in soils in southern Switzerland and northern Italy. Geoderma 2006, 136, 723-737. [CrossRef]

44. Rodríguez, M.R.; Velasco, F. Consideraciones ecológicas y bioquímicas sobre la humificación en sabinares desarrollados sobre material calizo y gneísico. Anal. Edafol. Agrobiol. 1988, 47, 1041-1053.

45. González, M.I.M.; Gallardo, J.F.; Egido, J.A. Evolución de la materia orgánica de un suelo climax y de un suelo de repoblación de la vertiente norte de la Sierra de Gata (Salamanca). Anal. Edafol. Agrobiol. 1977, 36, 1167-1186.

46. Tate, R.L. Soil Organic Matter: Biological and Ecological Effects; New York Wiley: New York, NY, USA, 1987; Volume 4, pp. 212-222.

47. Rosa, A.H.; Simoes, M.L.; de Oliveira, L.C.; Rocha, J.C.; Neto, L.M.; Milori, D.M.B.P. Multimethod study of the degree of humification of humic substances extracted from different tropical soil profiles in Brazil's Amazonian region. Geoderma 2005, 127, 1-10. [CrossRef]

48. Fuentes, M.; Gonzales-Gaitano, G.; Garcia Mina, J.M. The use and fullness of UV-visible and fluorescence spectroscopies to study the chemical nature of humic substances from soils compost. Org. Geochem. 2006, 37, 1949-1959. [CrossRef]

49. Aranda, V.; Oyonarte, C. Characteristics of organic matter in soil surface horizon derived from calcareous and metamorphic rocks and different vegetation types from the Mediterranean high-mountains in SE Spain. Eur. J. Soil Biol. 2006, 42, 247-258. [CrossRef]

50. Orlov, D.S.; Biryukova, O.N.; Rozanova, M.S. Revised system of the humus status parameters of soils and their genetic horizons. Eur. Soil Sci. 2004, 37, 798-805.

51. Belay-Tedla, A.; Zhou, X.; Su, B.; Wan, S.; Luo, Y. Labile, recalcitrant and microbial carbon and nitrogen pools of a tall grass prairie soil in the US Great Plains subjected to experimental warming and clipping. Soil Biol. Biochem. 2009, 41, 110-116. [CrossRef]

52. Charro, E.; Moyano, A.; Gallardo, J. Degradability of soils under oak and pine in Central Spain. Eur. J. For. Res. 2010, 129, 83-91. [CrossRef]

53. Swift, R.S. Sequestration of carbon by soil. Soil Sci. 2001, 166, 858-871. [CrossRef]

54. De Deyn, G.B.; Cornelissen, J.H.C.; Bardgett, R.D. Plant functional traits and soil carbon sequestration in contrasting biomes. Ecol. Lett. 2008, 11, 516-531. [CrossRef] [PubMed]

(C) 2017 by the authors. Licensee MDPI, Basel, Switzerland. This article is an open access article distributed under the terms and conditions of the Creative Commons Attribution (CC BY) license (http://creativecommons.org/licenses/by/4.0/). 